\title{
Synthesis of Barbaralones and Bullvalenes Made Easy by Gold Catalysis
}

\author{
Sofia Ferrer and Antonio M. Echavarren*
}

\begin{abstract}
The gold(I)-catalyzed oxidative cyclization of 7-ethynyl-1,3,5-cycloheptatrienes gives 1-substituted barbaralones in a general manner, which simplifies the access to other fluxional molecules. As an example, we report the shortest syntheses of bullvalene, phenylbullvalene, and disubstituted bullvalenes, and a readily accessible route to complex cagetype structures by further gold(I)-catalyzed reactions.
\end{abstract}

$\boldsymbol{F}_{\text {luxional molecules, such as barbaralone (1a), bullvalone }}$ (2a), and bullvalene (3a) have been central to the understanding of the phenomena of valence tautomerism (see Figure 1). ${ }^{[1,2]}$ These molecules undergo low energy [3.3]sigmatropic rearrangements, which in the case of bullvalene
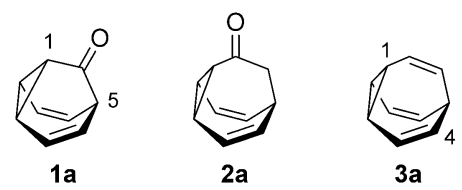

Figure 1. Barbaralone (1a), bullvalone (2a), and bullvalene (3a).

lead to 1209600 degenerate tautomers, ${ }^{[3-5]}$ whereas a lower number of constitutional isomers are possible for substituted bullvalenes ${ }^{[6-8]}$ and only two exist for barbaralone (1a). ${ }^{[9]}$

Syntheses of these fluxional molecules requires multistep procedures that proceed with low overall yield, often using explosive and toxic diazomethane. Thus, the optimized synthesis of barbaralone $(\mathbf{1 a})$, en route to bullvalene $(\mathbf{3 a} \mathbf{a}),{ }^{[10]}$ starts with the Büchner reaction of ethyl diazoacetate with benzene to form $\mathbf{4}^{[11,12]}$ which is converted into $\mathbf{1 a}$ in four steps via diazomethyl ketone $\mathbf{5}$ (Scheme 1) ${ }^{[10]}$ Bullvalene (3a)

\section{[*] S. Ferrer, Prof. A. M. Echavarren}

Institute of Chemical Research of Catalonia (ICIQ)

Barcelona Institute of Science and Technology

Av. Països Catalans 16, 43007 Tarragona (Spain)

E-mail: aechavarren@iciq.es

Prof. A. M. Echavarren

Departament de Química Analítica i Química Orgànica

Universitat Rovira i Virgili

C/ Marcel.li Domingo s/n, 43007 Tarragona (Spain)

(iD)

Supporting information and the ORCID identification number(s) for

the author(s) of this article can be found under http://dx.doi.org/10. 1002/anie.201606101.

of (c) 2016 The Authors. Published by Wiley-VCH Verlag GmbH \& Co. $\mathrm{KGaA}$. This is an open access article under the terms of the Creative Commons Attribution-NonCommercial License, which permits use, distribution and reproduction in any medium, provided the origina work is properly cited and is not used for commercial purposes.

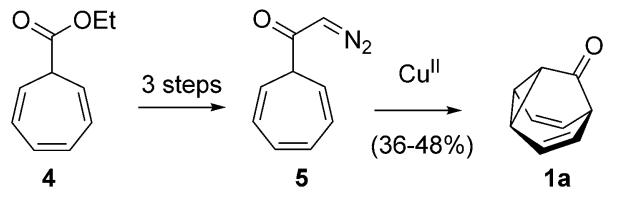

Scheme 1. Synthesis of barbaralone (1 a) from ethyl cyclohepta-2,4,6triene-1-carboxylate (4).

can be prepared from $\mathbf{1} \mathbf{a}$ in four additional steps by two different procedures by homologation of $\mathbf{1 a}$ to bullvalone (2a) with diazomethane. ${ }^{[2,10]}$ Barbaralone (1a) has also been prepared from (cyclooctatetraene)tricarbonyliron in two steps in approximately $36 \%$ yield. $^{[13]}$

1-Methylbarbaralone (1w) was prepared by a procedure similar to that shown in Scheme 1 using ethyldiazomethane in the reaction with cycloheptatriene carbamoyl chloride to form the homologue of $\mathbf{5}^{\left[{ }^{[9]}\right]}$ Although some ingenious syntheses of highly substituted bullvalenes have been designed, ${ }^{[8]}$ most bullvalenes have been prepared from parent 3a. Thus, for example, phenylbullvalene (3b) was obtained in three steps ( $26 \%$ yield) from $\mathbf{3 a}$ by dibromination, dehydrobromination with $\mathrm{KO} t \mathrm{Bu}$, and reaction of the resulting bromobullvalene with $\mathrm{Ph}_{2} \mathrm{CuLi}^{\left[{ }^{[7]}\right]}$

Current synthetic art does not allow preparation of substituted barbaralones in a general way, ${ }^{[14]}$ which limits the access to fluxional homologues and other theoretically interesting molecules. ${ }^{[12,15]}$ We have recently found that 7-aryl-1,3,5-cycloheptatrienes undergo a gold(I)-catalyzed retro-Büchner reaction to form highly reactive aryl gold(I) carbenes (a decarbenation reaction). ${ }^{[16]}$ However, 7-ethynyl1,3,5-cycloheptatrienes (6) react differently to form fluxional barbaralyl gold(I) intermediates 7; after a series of complex rearrangements $\mathbf{7}$ finally leads to indenes $\mathbf{8}$ and/or $\mathbf{9}$, depending on the gold catalyst (Scheme 2). ${ }^{[17]}$ Since the goldcatalyzed oxidation of alkynes has been shown to take place readily with oxidants such as sulfoxides, or amine- $N$-oxides to form $\alpha$-oxo $\operatorname{gold}(\mathrm{I})$ carbenes, ${ }^{[18,19]}$ we envisioned that the oxidation of intermediates 7 could lead to 1-substituted barbaralones 1 (Scheme 2). However, if the oxidation takes place directly on 7-ethynyl-1,3,5-cycloheptatrienes (6), the two regioisomeric $\alpha$-oxo gold(I) carbenes $10 \mathrm{a}$ and $\mathbf{1 0 b}$ would be formed, ${ }^{[18]}$ of which only $\mathbf{1 0 b}$ would lead to barbaralones $\mathbf{1}$ by intramolecular cyclopropanation.

Herein, we report a general and straightforward synthesis of 1-substituted barbaralones $\mathbf{1}$ from alkynes and commercially available tropylium tetrafluoroborate in just two steps by oxidative cyclization of 7-ethynyl-1,3,5-cycloheptatrienes.

We first studied the reaction of 7-(phenylethynyl)cyclohepta-1,3,5-triene $(\mathbf{6 b})$ with different gold(I) catalysts in the 


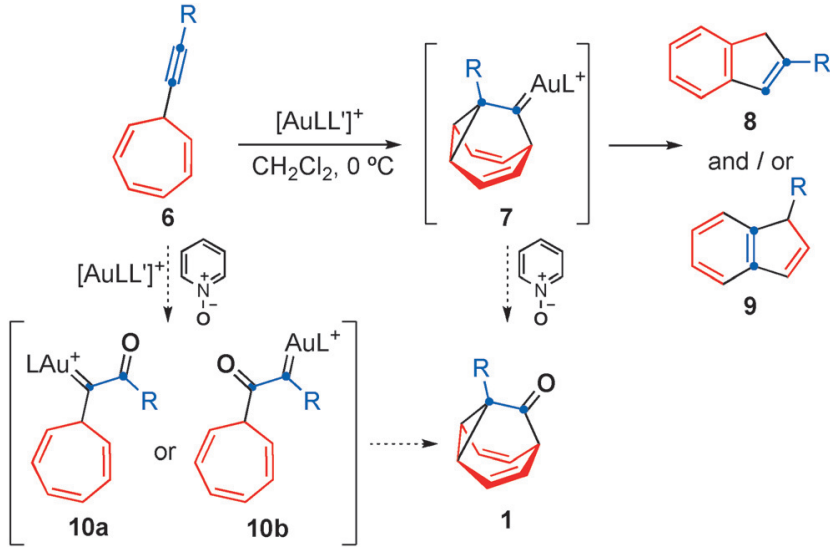

Scheme 2. Two different pathways for the formation of barbaralones 1 by gold(I)-catalyzed oxidative cyclization of 7-ethynyl-1,3,5-cycloheptatrienes (6)

presence of diphenylsulfoxide $\left(\mathbf{O} \mathbf{x}_{1}\right)$, and the $N$-oxides of pyridine $\left(\mathbf{O} \mathbf{x}_{2}\right)$, 3,5-dichloropyridine $\left(\mathbf{O} \mathbf{x}_{3}\right)$, or 8-methylquinoline $\left(\mathbf{O x}_{4}\right)$ as oxidants (Table 1). Using Johnphos gold(I) complex $\mathbf{A}$ in combination with $\mathbf{O} \mathbf{x}_{\mathbf{3}}$, 1-phenylbarbaralone (1) was obtained in $50 \%$ yield, together with 2-phenyl- $1 \mathrm{H}$ indene (8b; Table 1, entry 3). Related gold(I) complexes $\mathbf{B}$ and $\mathbf{C}$ led to $\mathbf{1} \mathbf{b}$ in lower yields in the presence of $\mathbf{O} \mathbf{x}_{\mathbf{3}}$ (Table 1, entries 5 and 6). The best yields of $\mathbf{1 b}$ were obtained using $[\operatorname{IPrAu}(\mathrm{MeCN})]\left[\mathrm{SbF}_{6}\right](\mathbf{D})$ and either $\mathbf{O x}_{\mathbf{1}}$ or $\mathbf{O x}_{3}$ (Table 1, respectively entries 7 and 9). Oxidants $\mathbf{O} \mathbf{x}_{\mathbf{2}}$ and $\mathbf{O} \mathbf{x}_{\mathbf{4}}$ led to very poor results (Table 1 , respectively entries 8 and 10). Interestingly, whereas phosphite gold(I) complex $\mathbf{E}$ afforded low yields (Table 1, entries 11 and 12), pycolinate gold(III) complex provided $\mathbf{1 b}$ in a similar yield in the presence of $\mathbf{O x}_{3}$ (Table 1, entry 14). Reactions of alkynes with pyridine- $N$ oxides can also be performed with Brønsted acids ${ }^{[20]}$ or $\mathrm{Zn}^{\mathrm{II}}$ catalysts. $^{[21]}$ However, in our system, a complex reaction mixture was obtained in the presence of methanesulfonic acid (Table 1, entry 15) and starting material was recovered when $\mathrm{Zn}(\mathrm{OTf})_{2}$ was used as the catalyst (Table 1, entry 16 ).

To assess the generality of this oxidative cyclization, various 7-ethynyl-1,3,5-cycloheptatrienes (6a-v) were prepared $^{[17]}$ and the combinations of catalyst and oxidant that provided the best results in the preliminary studies (conditions: A) cat. D, $\mathbf{O} \mathbf{x}_{\mathbf{1}}$; B) cat. $\mathbf{D}, \mathbf{O \mathbf { x } _ { \mathbf { 3 } }}$; C) cat. $\mathbf{A}, \mathbf{O x}_{\mathbf{3}}$ ) were tested on these substrates (Table 2). The most simple substrate, 7-ethynyl-1,3,5-cycloheptatriene (6a), produced barbaralone (1a) in $97 \%$ yield. The reaction was compatible with 7-(arylethynyl)-1,3,5-cycloheptatrienes $\mathbf{6 c - 0}$ bearing different $o-, m-$, or $p$ - substituents on the phenyl ring, such as methyl-, tert-butyl-, fluorine-, chlorine-, methoxy-, or trifluoromethyl-, affording the corresponding 1-substituted barbaralones $(\mathbf{1} \mathbf{c}-\mathbf{o})$ in moderate to good yields. Substrates $\mathbf{6 p - q}$, possessing a naphthyl or a thiophenyl substituent, gave barbaralones $\mathbf{1} \mathbf{p}-\mathbf{q}$ in yields up to $88 \%$. This catalytic procedure was extendible to alkynyl cycloheptatrienes with aliphatic or alkyl groups (6s-v), including $n$-butyl, $n$-hexyl, 2-phenylethyl, and cyclopropyl, giving the desired barbaralones $\mathbf{1 s - \mathbf { v }}$ in moderate to excellent yields. The reaction was also applicable to a substrate containing two alkynes (6r),
Table 1: Gold(I)-catalyzed oxidative reaction of $6 \mathrm{~b}$ to give 1-phenylbarbaralone (1 b)

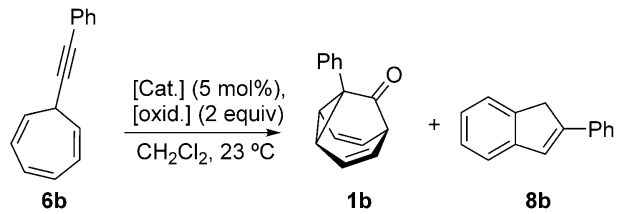

\begin{tabular}{|c|c|c|c|c|c|}
\hline Entry & [Cat.] & Oxid. & $\begin{array}{l}\text { Time } \\
{[\mathrm{h}]}\end{array}$ & $\begin{array}{c}1 \mathbf{b} \\
\text { Yield [\%] }^{[\mathrm{a}]}\end{array}$ & 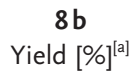 \\
\hline 1 & A & $O x_{1}$ & 2.5 & 12 & 58 \\
\hline 2 & A & $\mathrm{Ox}_{2}$ & 16 & 5 & - \\
\hline 3 & A & $\mathrm{Ox}_{3}$ & 2.5 & $50(50)^{[b]}$ & 28 \\
\hline 4 & A & $\mathrm{Ox}_{4}$ & 16 & 23 & - \\
\hline 5 & B & $\mathrm{Ox}_{3}$ & 3 & 30 & 36 \\
\hline 6 & C & $\mathrm{Ox}_{3}$ & 3 & 32 & 42 \\
\hline 7 & D & $\mathrm{Ox}_{1}$ & 3 & $(83)^{[b]}$ & - \\
\hline 8 & D & $\mathrm{Ox}_{2}$ & 24 & 2 & - \\
\hline 9 & D & $\mathrm{Ox}_{3}$ & 3 & 64 & - \\
\hline 10 & D & $\mathrm{Ox}_{4}$ & 3 & 7 & - \\
\hline 11 & $E$ & $O x_{1}$ & 2.5 & 20 & - \\
\hline 12 & $E$ & $\mathrm{Ox}_{3}$ & 2.5 & 30 & - \\
\hline 13 & $\mathbf{F}$ & $O x_{1}$ & 5 & 14 & 61 \\
\hline 14 & $\mathbf{F}$ & $\mathrm{Ox}_{3}$ & 5 & 61 & - \\
\hline 15 & $\mathrm{MeSO}_{3} \mathrm{H}^{[\mathrm{c}]}$ & $\mathrm{Ox}_{3}$ & 2.5 & \multicolumn{2}{|c|}{ complex mixture } \\
\hline 16 & $\mathrm{Zn}(\mathrm{OTf})_{2}^{[\mathrm{d}]}$ & $\mathrm{Ox}_{3}$ & 24 & \multicolumn{2}{|c|}{ starting material } \\
\hline
\end{tabular}

[a] Yields determined by ${ }^{1} \mathrm{H}$ NMR using mesitylene as an internal standard. [b] Yield of isolated products. [c] 4 equiv [d] $10 \mathrm{~mol} \%$. Catalyst (cat.), oxidant (oxid.).

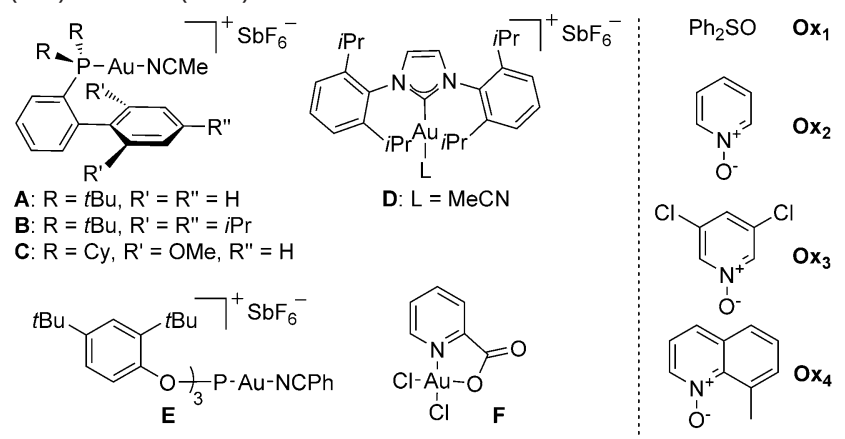

affording dibarbaralone $1 \mathbf{r}$ in $60 \%$ yield. The process was efficiently scalable, providing up to $850 \mathrm{mg}$ of barbaralone (1a) in one run in $96 \%$ yield. Mechanistically, the formation of aryl substituted barbaralones $\mathbf{1 b}-\mathbf{r}$ strongly suggests that the oxidation takes place on barbaralyl gold(I) intermediates 7 (Scheme 2), rather than on the alkyne, which would favor formation of unproductive intermediate $\mathbf{1 0 a}$ by benzylic oxidation. ${ }^{[18]}$

The introduction of a methyl substituent was found to shift the sigmatropic equilibrium toward the 1-substituted isomer (Scheme 3). ${ }^{[6 c, 9 b]}$ Our NMR data show that 1-substituted barbaralones are in all cases the most stable tautomers, as confirmed by the X-ray diffraction structures of $\mathbf{1} \mathbf{a}-\mathbf{d}, \mathbf{1} \mathbf{q}$, and $\mathbf{1 r}$ (Table 2). ${ }^{[22]}$

With the synthesis of barbaralones (1) in hand, and the preparation of bullvalenes (3) in mind, we examined the applicability of this oxidative cyclization for the synthesis of bullvalone (2a) using propargyl cycloheptatriene as substrate 
Table 2: Gold(I)-catalyzed oxidative synthesis of barbaralones $1 \mathbf{a}-\mathbf{v}$.
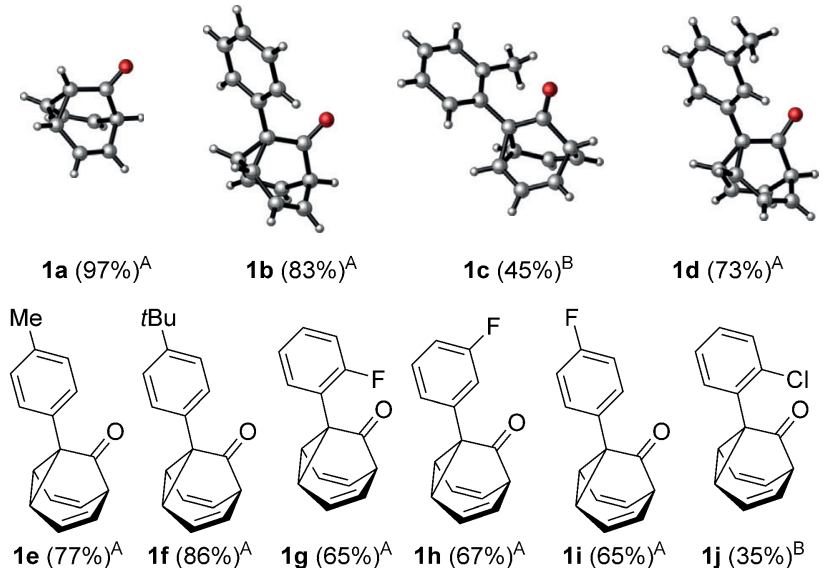

1b $(83 \%)^{A}$

1c $(45 \%)^{\mathrm{B}}$
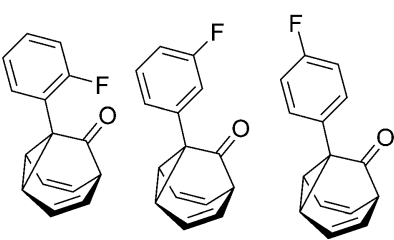

1d $(73 \%)^{A}$

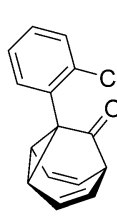

$1 \mathrm{i}(65 \%)^{\mathrm{A}} \quad 1 \mathrm{j}(35 \%)^{\mathrm{B}}$
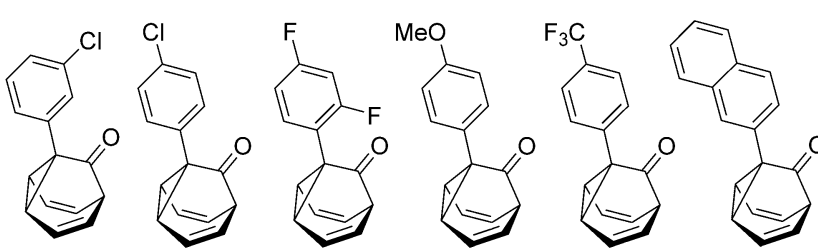

$1 \mathrm{k}(69 \%)^{\mathrm{A}}$
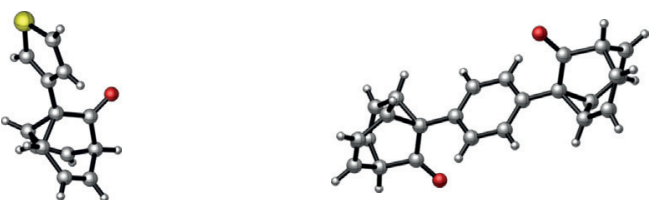

1q $(88 \%)^{A}$

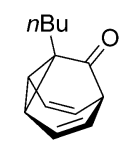

1s $(45 \%)^{\mathrm{C}}$

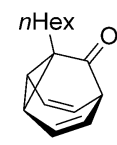

1t $(46 \%)^{\mathrm{A}}$

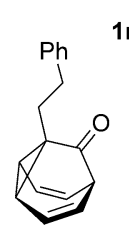

1u $(45 \%)^{A}$ $\operatorname{1r}(60 \%)^{\mathrm{B}}$

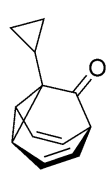

1v $(91 \%)^{\mathrm{B}}$

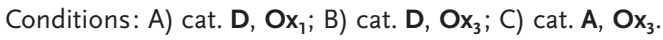

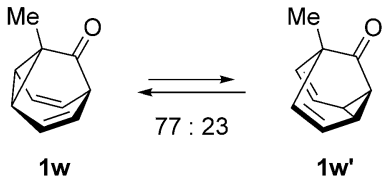

Scheme 3. Equilibrium between 1-methyl- and 5-methylbarbaralones. ${ }^{[9 b]}$

(11). Thus, the reaction of propargyl cycloheptatriene (11) with different gold(I) catalysts in the presence of the previously employed oxidants was investigated (Table 3). However, instead of the desired bullvalone, arising from a 5-endo-dig oxidative cyclization, in all cases we observed the recovered starting material or formation of 1-formylbarbaralane (12), ${ }^{[22]}$ the product of a 5-exo-dig process. While Johnphos gold(I) complex A gave poor results regardless of the oxidant used (Table 3, entries 1-4), good yields were obtained with $t$ BuXPhos gold(I) catalyst $\left(\mathbf{B}^{\prime}\right)$ and [IPrAu$(\mathrm{MeCN}) \mathrm{SbF}_{6}(\mathbf{D})$ with $\mathbf{O x}_{\mathbf{1}}$ (Table 3, entries 5 and 8). A
Table 3: Gold(I)-catalyzed oxidative reaction of propargyl cycloheptatriene (11) to give 1-formylbarbaralane (12).
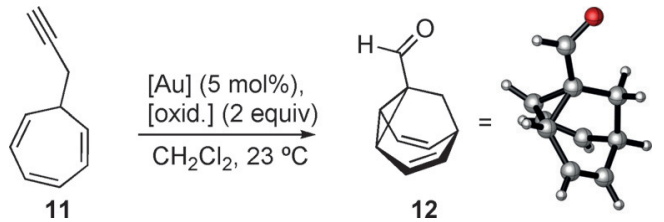

\begin{tabular}{|c|c|c|c|c|}
\hline Entry & {$[\mathrm{Au}]$} & Oxid. & $\begin{array}{c}\text { Time } \\
{[\mathrm{h}]}\end{array}$ & $\begin{array}{c}12 \\
{\text { Yield }[\%]^{[a]}}^{[a}\end{array}$ \\
\hline 1 & A & $O x_{1}$ & 18 & 27 \\
\hline 2 & A & $\mathrm{Ox}_{2}$ & 15 & - \\
\hline 3 & A & $\mathrm{Ox}_{3}$ & 18 & 5 \\
\hline 4 & A & $\mathrm{Ox}_{4}$ & 15 & - \\
\hline 5 & $\mathbf{B}^{\prime}$ & $O x_{1}$ & 17 & $91(87)^{[b]}$ \\
\hline 6 & $\mathbf{B}^{\prime}$ & $O x_{3}$ & 17 & 7 \\
\hline 8 & D & $O x_{1}$ & 4 & $90(87)^{[b]}$ \\
\hline 9 & D & $\mathrm{Ox}_{3}$ & 18 & 8 \\
\hline 10 & $\mathbf{E}^{\prime}$ & $O x_{1}$ & 6 & 92 \\
\hline 11 & $\mathbf{E}^{\prime}$ & $\mathrm{Ox}_{3}$ & 24 & - \\
\hline
\end{tabular}

[a] Yields determined by ${ }^{7} \mathrm{H}$ NMR spectroscopy using mesitylene as an internal standard. [b] Yield of isolated products.

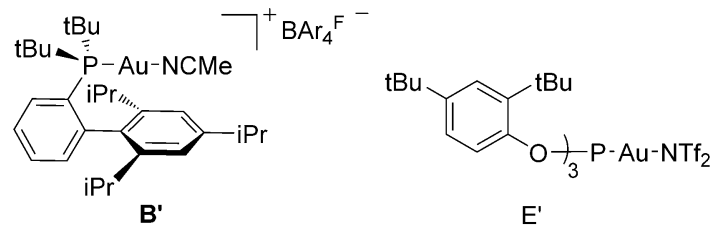

better yield of aldehyde $\mathbf{1 2}$ was obtained using phosphite gold(I) complex $\mathbf{E}^{\prime}$ and $\mathbf{O} \mathbf{x}_{\mathbf{1}}$ (Table 3, entry 10).

At this stage we considered accessing bullvalones (2) via barbaralones (1) en route to bullvalenes (3). Homologation of 1a with diazomethane has been reported to give bullvalone (2a) in $24 \%$ yield along with an isomeric aldehyde $(34 \%))^{[2,10]}$ Reduction of $\mathbf{2}$ a followed by acetylation led to the corresponding acetate ( $40 \%$, two steps), which was pyrolyzed at $345^{\circ} \mathrm{C}$ to give a $1: 1$ ratio of bullvalene (3a) and cis-9,10dihydronaphthalene. ${ }^{[2,23]}$ An improved procedure was reported via bullvalone tosylhydrazone, providing bullvalene (3a) in approximately $5 \%$ yield from $\mathbf{2 a}$ in four steps. ${ }^{[10,24]}$

In our new approach, bullvalene (3a) and phenylbullvalene (3b) were prepared from barbaralones $\mathbf{1} \mathbf{a}-\mathbf{b}$ by a threestep procedure. A homologation reaction of $\mathbf{1 a}$ and $\mathbf{1 b}$ with the lithium anion of (trimethylsilyl)diazomethane ${ }^{[25]}$ gave bullvalones $\mathbf{2 a}$ and $\mathbf{2 b}$ in 37 and $22 \%$ yield, respectively (Scheme 4). Formation of the corresponding enol triflates using LDA and Comins' reagent, or LiHMDS and $\mathrm{PhNTf}_{2}$ followed by immediate reduction with $n \mathrm{Bu}_{3} \mathrm{SnH}$ and $\mathrm{Pd}\left(\mathrm{PPh}_{3}\right)_{4}$ as catalyst, ${ }^{[26]}$ afforded $\mathbf{3 a}$ and $\mathbf{3} \mathbf{b}^{[27]}$ in $44 \%$ and $60 \%$ yield, respectively, whose structures were confirmed by X-ray diffraction. ${ }^{[22]}$ This new synthesis of bullvalene (3a) is the most efficient to date as it requires a total of five steps (10\% overall yield) from commercially available tropylium tetrafluoroborate and ethynyl magnesium bromide.

Various disubstituted bullvalenes $\mathbf{3} \mathbf{c}-\mathbf{e}$ were also prepared from phenyl bullvalone (2) through sequential formation of the enol triflate followed by Stille couplings (Scheme 4). ${ }^{[28]}$ 


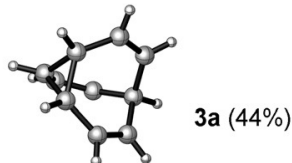

1. LiHMDS, PhNTf

2. $n \mathrm{Bu}_{3} \mathrm{SnH}, \mathrm{LiCl}$

$\mathrm{Pd}\left(\mathrm{PPh}_{3}\right)_{4}$

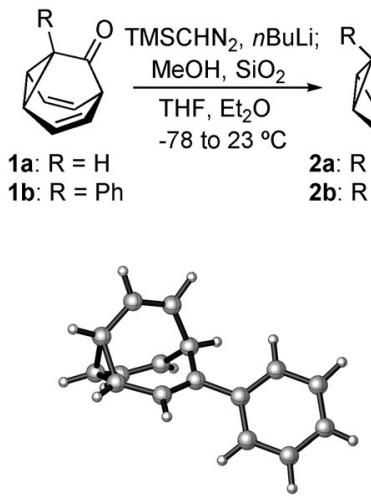

3b

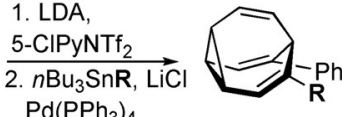

$\mathrm{Pd}\left(\mathrm{PPh}_{3}\right)_{4}$

3b: $\mathbf{R}=\mathbf{H}(60 \%)$ 3c: $\mathbf{R}=\operatorname{Ph}(15 \%)$ 3d: $\mathbf{R}=\operatorname{vinyl}(58 \%)$ 3e: $\mathbf{R}=$ allyl $(37 \%)$

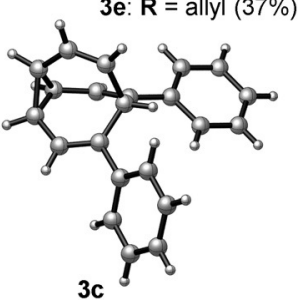

Scheme 4. Synthesis of bullvalene ( $3 a$ ), phenylbullvalene $(\mathbf{3 b})$, and disubstituted bullvalenes $3 \mathbf{c}-\mathbf{e}$.

The molecular structure of diphenyl bullvalene $\mathbf{3 c}$ was determined by X-ray diffraction. ${ }^{[22]}$ Bullvalenes $\mathbf{3} \mathbf{c}-\mathbf{e}$ were in equilibrium with the 3,6- and 3,7-disubstituted isomers at $-40^{\circ} \mathrm{C}$; the observed ratios of the respective compounds was 7.6:5.7:1, 5.2:1.5:1, and 3.8:2.3:1..$^{[7 \mathrm{~d}]}$

Barbaralones $1 \mathbf{a}$ and $\mathbf{1 b}$ were converted into $14 \mathbf{a}$ and $\mathbf{1 4 b}$ in two steps by the addition of ethynyl magnesium bromide and subsequent gold(I)-catalyzed reaction of the corresponding alcohols $\mathbf{1 3} \mathbf{a}$ and $\mathbf{1 3 b}$, which proceeded by a new type of

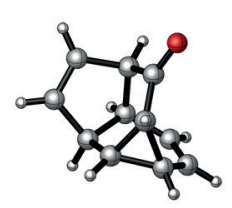

$14 a$

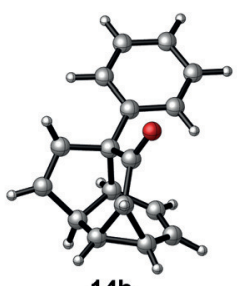

$14 b$ 1a-b $\underset{\substack{\mathrm{THF} \\ 0 \text { to } 23^{\circ} \mathrm{C}}}{\equiv}$

13b: $\mathrm{R}=\mathrm{Ph}(88 \%)$

a) Cat. D (5 mol\%) b) Cat. A (5 mol\%) $\mathrm{CH}_{2} \mathrm{Cl}_{2}, 23^{\circ} \mathrm{C}$

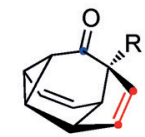

14a: $R=H(55 \%)$

14b: $\mathrm{R}=\mathrm{Ph}(83 \%)$
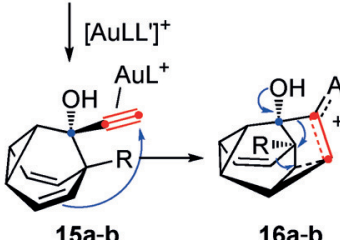

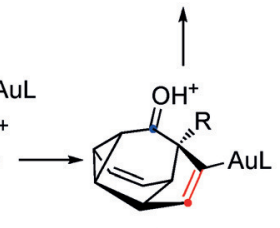

$17 a-b$

Scheme 5. Preparation of highly fused tetracyclic molecules $14 \mathrm{a}$ and $14 \mathrm{~b}$.

cyclization/rearrangement (Scheme 5). Structures 14a and 14b were confirmed by X-ray diffraction. ${ }^{[22]}$

Unprecedented tetracyclic cages $14 \mathbf{a}$ and $\mathbf{1 4 b}$ are probably formed by coordination of gold(I) of the alkyne of the minor tautomer of $13 \mathbf{a}$ and $\mathbf{1 3} \mathbf{b}$ to give $15 \mathbf{a}$ and $\mathbf{1 5} \mathbf{b}$, followed by intramolecular attack of the alkene to form delocalized intermediates $\mathbf{1 6} \mathbf{a}$ and $\mathbf{1 6} \mathbf{b}^{[29,30]}$ and semipinacol-type rearrangement to give 17 a and $\mathbf{1 7} \mathbf{b}$ (Scheme 5). To the best of our knowledge, and despite the many different types of gold(I)catalyzed cycloisomerizations, ${ }^{[30]}$ this formation of a fivemembered ring by cyclization-rearrangement is unprecedented.

Furthermore, alkylation of barbaralol $\mathbf{1 8}^{[22]}$ with propargyl bromide gives 1,7-enyne 19, which undergoes an exo-dig cyclization with gold(I) catalyst $\mathbf{D}$ to form intermediate $\mathbf{2 0},{ }^{[30]}$ which then reacts with methanol as a nucleophile to form tricyclic system 21 (Scheme 6).

1a $\frac{\mathrm{LiAlH}_{4}}{\mathrm{Et}_{2} \mathrm{O}, 0^{\circ} \mathrm{C}}$

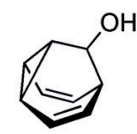

$18(92 \%)$

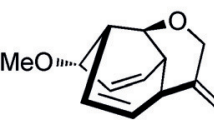

$21(54 \%)$
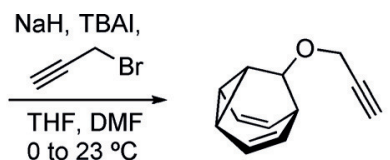

$19(78 \%)$

Cat. D $\mathrm{MeOH}, \mathrm{CH}_{2} \mathrm{Cl}_{2}$ (5 mol\%) $2^{\circ} \mathrm{C}$

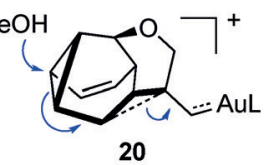

Scheme 6. Formation of tricyclic derivative 21 from barbaralol (18).

In summary, we have developed an efficient synthesis of 1-substituted barbaralones by gold(I)-catalyzed oxidative cyclization of 7-(substituted ethynyl)-1,3,5-cycloheptatrienes. This method has allowed accomplishment of the shortest syntheses of bullvalene and other substituted bullvalenes. Thus, parent bullvalene (3a) is obtained in five steps from commercially available starting materials in $10 \%$ overall yield, which compares favorably with previous procedures that require nine or more steps and proceeded with very low overall efficiency. The straightforward access to barbaralones opens a way to obtain complex cage systems with unprecedented molecular architectures.

\section{Acknowledgements}

We thank MINECO (Severo Ochoa Excellence Accreditation 2014-2018 (SEV-2013-0319) CTQ2013-42106-P), the MEC (FPU fellowship to SF), the European Research Council (Advanced Grant No. 321066), the AGAUR (2014 SGR 818), and the ICIQ Foundation. We also thank the ICIQ X-ray diffraction unit and Dr. Michael E. Muratore for helpful discussions. 
Keywords: barbaralones - bullvalenes - cyclization reactions . gold $\cdot$ valence tautomerism

How to cite: Angew. Chem. Int. Ed. 2016, 55, 11178-11182 Angew. Chem. 2016, 128, 11344-11348

[1] a) W. v. E. Doering, W. R. Roth, Angew. Chem. Int. Ed. Engl. 1963, 2, 115-122; Angew. Chem. 1963, 75, 27-35; b) R. V. Williams, Chem. Rev. 2001, 101, 1185-1204; c) D. A. Hrovat, E. C. Brown, R. V. Williams, H. Quast, W. T. Borden, J. Org. Chem. 2005, 70, 2627-2632; d) M. He, J. W. Bode, Proc. Natl. Acad. Sci. USA 2011, 108, $14752-14756$.

[2] a) W. v. E. Doering, W. R. Roth, Tetrahedron 1963, 19, 715-737; b) W. V. E. Doering, B. M. Ferrier, E. T. Fossel, J. H. Hatenstein, M. Jones, Jr., G. Klumpp, R. M. Rubin, M. Saunders, Tetrahedron 1967, 23, 3943-3963.

[3] a) G. Schröder, Angew. Chem. Int. Ed. Engl. 1963, 2, 481; Angew. Chem. 1963, 75, 722; b) G. Schröder, Chem. Ber. 1964, 97, 3140 3149; c) R. Merényi, J. F. M. Oth, G. Schröder, Chem. Ber. 1964 97, 3150-3161; d) G. Schröder, J. F. M. Oth, R. Merényi, Angew. Chem. Int. Ed. Engl. 1965, 4, 752-761; Angew. Chem. 1965, 77, 774-784; e) J. F. M. Oth, K. Müllen, J.-M. Gilles, G. Schröder, Helv. Chim. Acta 1974, 57, 1415-1433.

[4] M. Saunders, Tetrahedron Lett. 1963, 4, 1699-1702.

[5] a) R. Poupko, H. Zimmermann, Z. Luz, J. Am. Chem. Soc. 1984 106, 5391-5394; b) B. H. Meier, W. L. Earl, J. Am. Chem. Soc. 1985, 107, $5553-5555$; c) P. Luger, K. Roth, J. Chem. Soc. Perkin Trans. 2 1989, 649-655; d) J. J. Titman, Z. Luz, H. W. Spiess, J. Am. Chem. Soc. 1992, 114, 3765-3771; e) S. Schlick, Z. Luz, R. Poupko, J. Am. Chem. Soc. 1992, 114, 4315-4320.

[6] a) R. Poupko, H. Zimmermann, K. Müller, Z. Luz, J. Am. Chem. Soc. 1996, 118, 7995-8005; b) K. Müller, H. Zimmermann, C. Krieger, R. Poupko, Z. Luz, J. Am. Chem. Soc. 1996, 118, 80068014 ; c) R. Poupko, K. Müller, C. Krieger, H. Zimmermann, Z. Luz, J. Am. Chem. Soc. 1996, 118, 8015-8023; d) Z. Luz, L. Olivier, R. Poupko, K. Müller, C. Krieger, H. Zimmermann, J. Am. Chem. Soc. 1998, 120, 5526-5538.

[7] a) B. Volkmann, G. Schröder, Chem. Ber. 1984, 117, 2226-2232; b) K. Rebsamen, G. Schröder, Chem. Ber. 1993, 126, 1419-1423; c) K. Rebsamen, G. Schröder, Chem. Ber. 1993, 126, 1425-1427; d) K. Rebsamen, H. Röttele, G. Schröder, Chem. Ber. 1993, 126, 1429-1433.

[8] a) A. R. Lippert, J. Kaeobamrung, J. W. Bode, J. Am. Chem. Soc. 2006, 128, $14738-14739$; b) A. R. Lippert, V. L. Keleshian, J. W. Bode, Org. Biomol. Chem. 2009, 7, 1529-1532; c) A. R. Lippert, A. Naganawa, V. L. Keleshian, J. W. Bode, J. Am. Chem. Soc 2010, 132, 15790-15799; d) K. K. Larson, M. He, J. F. Teichert, A. Naganawa, J. W. Bode, Chem. Sci. 2012, 3, 1825-1828; e) M. He, J. W. Bode, Org. Biomol. Chem. 2013, 11, $1306-1317$; f) J. F. Teichert, D. Mazunin, J. W. Bode, J. Am. Chem. Soc. 2013, 135, 11314-11321.

[9] a) J. B. Lambert, Tetrahedron Lett. 1963, 4, 1901-1906; b) J. C. Barborak, S. Chari, P. v. R. Schleyer, J. Am. Chem. Soc. 1971, 93, 5275-5277; c) H. Nakanishi, O. Yamamoto, Chem. Lett. 1975, 513-516; d) C. Engdahl, P. Ahlberg, J. Am. Chem. Soc. 1979, 101, 3940-3946; e) E. R. Johnston, J. S. Barber, M. Jacomet, J. C. Barborak, J. Am. Chem. Soc. 1998, 120, 1489-1493.

[10] J. Casas, F. Serratosa, An. Quím. 1977, 73, 300-302.

[11] M. J. S. Dewar, R. Pettit, J. Chem. Soc. 1956, 2021-2025.

[12] For two alternative procedures, see: E. Vedejs, R. A. Gabel, P. D. Weeks, J. Am. Chem. Soc. 1972, 94, 5842-5845.
[13] V. Heil, B. F. G. Johnson, J. Lewis, D. J. Thompson, J. Chem. Soc. Chem. Commun. 1974, 270-271.

[14] For cyclopentannulated barbaralones by photocycloaddition of 2-(pent-4-yn-1-yl)tropones, see: K. S. Feldman, J. H. Come, G. J. Fegley, B. D. Smith, M. Parvez, Tetrahedron Lett. 1987, 28, 607 610.

[15] S. Kirchmeyer, A. de Meijere, Helv. Chim. Acta 1990, 73, 1182 1196.

[16] a) C. R. Solorio-Alvarado, Y. Wang, A. M. Echavarren, J. Am. Chem. Soc. 2011, 133, 11952-11955; b) Y. Wang, P. McGonigal, B. Herlé, M. Besora, A. M. Echavarren, J. Am. Chem. Soc. 2014, 136, $801-809$.

[17] P. R. McGonigal, C. de León, Y. Wang, A. Homs, C. R. SolorioAlvarado, A. M. Echavarren, Angew. Chem. Int. Ed. 2012, 51, 13093-13096; Angew. Chem. 2012, 124, 13270-13273.

[18] a) L. Zhang, Acc. Chem. Res. 2014, 47, 877-888; b) Z. Zheng, Z. Wang, Y. Wang, L. Zhang, Chem. Soc. Rev. 2016, DOI: 10.1039/ c5cs00887e.

[19] a) D. Vasu, H.-H. Hung, S. Bhunia, S. A. Gawade, A. Das, R.-S. Liu, Angew. Chem. Int. Ed. 2011, 50, 6911-6914; Angew. Chem. 2011, 123, 7043-7046; b) D. B. Huple, S. Ghorpade, R.-S. Liu, Adv. Synth. Catal. 2016, 358, 1348-1367; c) J. Schulz, J. Jasik, A. Gray, J. Roithová, Chem. Eur. J. 2016, 22, DOI: 10.1002/ chem.201601634, and references therein.

[20] D.-F. Chen, Z.-Y. Han, Y.-P. He, J. Yu, L.-Z. Gong, Angew. Chem. Int. Ed. 2012, 51, 12307-12310; Angew. Chem. 2012, 124, $12473-12476$.

[21] L. Li, B. Zhou, Y.-H. Wang, C. Shu, Y.-F. Pan, X. Lu, L.-W. Ye, Angew. Chem. Int. Ed. 2015, 54, 8245-8249; Angew. Chem. 2015, 127, 8363 - 8367.

[22] CCDC 1487016 (1a), CCDC 1487017 (1b), CCDC 1487018 (1c), CCDC 1487019 (1d), CCDC 1487020 (1q), CCDC 1487021 (1r), CCDC 1487022 (2b), CCDC 1487023 (3a), CCDC 1487024 (3b), CCDC $1487025 \quad$ (3c), CCDC $1487026 \quad$ (12), CCDC 1487027 (14a), and CCDC 1487028 (14b) contain the supplementary crystallographic data for this paper. These data can be obtained free of charge from The Cambridge Crystallographic Data Centre.

[23] The yield for the last step was not provided in the original report. ${ }^{[2 b]}$

[24] a) F. Serratosa, F. López, J. Font, Tetrahedron Lett. 1972, 2589 2590; b) F. Serratosa, F. López, J. Font, An. Quím. 1974, 70, 893 899.

[25] H. Liu, C. Sun, N.-K. Lee, R. F. Henry, D. Lee, Chem. Eur. J. 2012, 18, 11889-11893.

[26] W. J. Scott, J. K. Stille, J. Am. Chem. Soc. 1986, 108, 3033-3040.

[27] Phenylbullvalene $\mathbf{3 b}$ has been shown to be in a 3:1 equilibrium with the 3 -substituted isomer at $-40^{\circ} \mathrm{C} .^{[7 \mathrm{~d}]}$ We have confirmed this result and have observed that the equilibrium can be shifted to $5.6: 1$ at $-90^{\circ} \mathrm{C}$.

[28] W. J. Scott, G. T. Crisp, J. K. Stille, J. Am. Chem. Soc. 1984, 106, $4630-4632$.

[29] V. López-Carrillo, N. Huguet, Á. Mosquera, A. M. Echavarren, Chem. Eur. J. 2011, 17, $10972-10978$.

[30] a) E. Jiménez-Núñez, A. M. Echavarren, Chem. Rev. 2008, 108, 3326-3350; b) R. Dorel, A. Echavarren, Chem. Rev. 2015, 115, 9028-9072; c) R. Dorel, A. M. Echavarren, J. Org. Chem. 2015, $80,7321-7332$.

Received: June 23, 2016

Published online: August 22, 2016 